\title{
ESPAÇO SAGRADO EM PRESIDENTE PRUDENTE - PARÓQUIA SANTO ANTÔNIO DE PÁDUA
}

André Ferreira Damaceno, Fabrícia Dias da Cunha de Moraes Fernandes Borges.

Universidade do Oeste Paulista - UNOESTE, Curso de Engenharias e Arquitetura e Urbanismo, Presidente Prudente, SP. E-mail: andree_damacenoo@hotmail.com.

\section{RESUMO}

O presente trabalho consiste na explanação teórica acerca do espaço sagrado do Catolicismo, apresentado a origem e o respectivo desenvolvimento do mesmo, para que as transformações ocorridas, exemplifiquem toda transcendência simbólica pertinente para a transmissão de mensagens na arquitetura sacra Contemporânea, assim como as necessidades básicas para o acolhimento humanitário aos cristãos, favorecendo a espiritualidade e a vida em comunidade. A metodologia consistiu em uma investigação bibliográfica e levantamentos do objeto de estudo, a fim de verificar como esses elementos estão presentes. Assim sendo, os feitos conquistados pela Igreja Católica no mundo refletiram para a instauração da religião em Presidente Prudente e para o surgimento das comunidades, em especial a Paróquia Santo Antônio de Pádua que colabora para intensificar a memória, o recolhimento e a introspecção.

Palavras-chave: Espaço Sagrado, Transmissão de Mensagens, Acolhimento Humanitário, Vida em Comunidade, Memória.

\section{SACRED SPACE IN PRESIDENTE PRUDENTE - PARISH OF SAINT ANTHONY OF PADUA.}

\begin{abstract}
The present work consists of the theoretical explanation upon the Sacred Space of the Catholicism, it presents the origin and the respective development of the ones mentioned, so that the transformations made exemplify all the symbolic transcendence relevant to the transmission of messages in Contemporary Sacra Architecture, as well as the basic needs for the human reception of Christians favoring spirituality and community life. The methodology consisted of a bibliographical investigation and surveys of the object of study in order to verify how these elements are present. Therefore, the achievements of the Catholic Church in the world reflected in the establishment of the Catholic religion in Presidente Prudente and in the emergence of communities, especially the parish of Saint Anthony of Padua which collaborates to intensify the memory, the contemplation and the introspection.
\end{abstract}

Keywords: Sacred Space, Transmission of messages, Human Reception, Community Life, Memory. 


\section{INTRODUÇÃO}

Desde as primícias a humanidade produz espaços sagrados que condicionam a prática religiosa. Porém na história do Catolicismo, vertente religiosa pertencente ao Cristianismo, as Igrejas eram durante séculos edificadas sem abertura para os fiéis participarem da vida da comunidade. Somente a partir do Concílio Vaticano II, na década de 1960, que os templos Cristãos passaram a estabelecer aproximação com os seus seguidores e para isso os espaços sagrados contemporâneos necessitam transparecer acolhimento e condições dignas para as atividades evangelizadoras (OLIVEIRA, 2012).

Através da arte e da sua relação permanente com o sagrado, as representações artísticas possuem a característica de transmitir mensagens e proporcionar a vivência de sentimentos e emoções particulares aos fiéis, fato que se verifica ao longo de toda a evolução dos espaços de culto. Mas, assim como as coisas se alteram ao longo da vida, a maneira como a expressão é trabalhada pelos homens também sofre transformações, pelo fato de cada sociedade compreender e enxergar o mundo de uma visão diferente e também pela necessidade de retirar os simbolismos em excesso proposto para as Igrejas do século XXI (RESENDE, 2015).

Diante desse contexto, foi analisada a relevância histórica e os valores mensuráveis e imensuráveis da Igreja Matriz da Paróquia de Santo Antônio de Pádua localizada no bairro Jardim Paulista em Presidente Prudente-SP, para se obter a compreensão da importância desse espaço sagrado para a propagação do Catolicismo na cidade.

\section{METODOLOGIA}

A metodologia se baseia numa investigação bibliográfica, buscando o entendimento acerca do desenvolvimento dos espaços sagrados e dos conceitos simbólicos e afetivos que estão atrelados a essa temática. Além disso, foram realizados levantamentos in loco visando a melhor compreensão do objeto de estudo, utilizando-se para isso de fotografias, verificações métricas e observações comportamentais.

\section{DISCUSSÃO}

De acordo com Brandão (2011), os espaços religiosos do Catolicismo possuem grande complexidade em seu conceito geral, porque são locais em que o ser humano se relaciona diretamente com um ser transcendente que não pode ser visto e nem tocado, apenas sentido através da fé e da espiritualidade. Trata-se de espaços "onde Deus, através de Jesus Cristo, chama, convoca, fala e celebra a aliança com seu povo" (PASTRO, 1999, Apud. BRANDAO, 2011, p. 10).

Os cristãos, ao longo de toda a história da humanidade, sempre consideraram o mundo impuro e desprotegido das maldades causadas pelos homens não crentes, e, por isso, buscam locais em que podem expressar a crença em Deus, fazendo com que a presença do sagrado seja o enfoque principal. Segundo Corrêa (2001, Apud. OLIVEIRA, 2012, p. 144), "o espaço vivido é uma experiência contínua, egocêntrica e social, um espaço de movimento e um espaço-tempo vivido que se refere ao afetivo, ao mágico, ao imaginário", onde os simbolismos podem fomentar as emoções espirituais (OLIVEIRA, 2012).

Segundo Brandão (2011) e Gympel (2001), antes da liberdade para expressar a crença a Deus os cristãos não podiam utilizar edifícios oficiais, eram obrigados a se reunirem em locais de refúgio com pouco valor arquitetônico. As primeiras basílicas foram surgir somente durante o Império Romano, se contrapondo aos templos das antigas 
civilizações onde vários deuses eram adorados e os seus fiéis não podiam estar dentro do espaço de culto. Esse novo panorama fez com que fossem necessários locais espaçosos devido ao demasiado número de cristãos.

Nas paredes dos espaços sagrados, as expressões artísticas incorporavam através de mosaicos, a doutrina cristã com toda a retratação histórica vivenciada na pessoa de Jesus Cristo, servindo como uma bíblia ilustrativa para os fiéis que não tinham o conhecimento da leitura. Porém, na Idade Média, os simbolismos passaram a ser considerados apenas instrumentos de admiração, perdendo a linguagem original e deixando margem para mudanças (FRADE, 2012).

Segundo Captivo (2016), o Movimento Litúrgico, surgido em 1909 na Bélgica, que tinha o desejo de regresso as fontes do cristianismo, maior participação comunitária dos fiéis durante as celebrações e a inserção do altar como o foco nos ritos litúrgicos eucarísticos, foi essencial para a conferencia do Concílio Vaticano II na década de 1960 e para dessa forma alcançar o conceito existente para a organização das Igrejas Contemporâneas.

A Constituição Sacrosanctum Concilium, documento promulgado na conferência, expôs a necessidade que a funcionalidade litúrgica exige no momento em que os espaços sagrados são idealizados, tendo que ser pensados de dentro para fora, ou seja, da organização dos ritos para a forma, pois assim os cristãos podem ser mais participativos (BRANDÃO, 2011). Dentre as modificações, o altar passou a ser a essência interna das Igrejas com a posição central do presbitério, sendo mais próximo da assembleia após a retirada dos obstáculos e maior aproximação espacial (CAPTIVO, 2016).

De acordo com Brandão (2011), a Constituição Sacrosanctum Concilium ainda apresentou orientações referentes ao uso de imagens no espaço de culto. Estas devem ser expostas com moderação, representando a beleza de forma nobre e não com toda abundancia de nobreza que existia anteriormente. Suas exposições devem servir de apoio e finalidade para a liturgia e não simplesmente para o gosto artístico.

Nesse novo cenário da Igreja Católica Apostólica Romana, a arquitetura Contemporânea sucedeu o Modernismo e tornou-se fundamental para transformação dos conceitos pedidos no ultimo Concílio em vigência, o Vaticano II. Além dos espaços existentes para os ritos litúrgicos, é muito comum encontrar salas de reuniões e ambientes administrativos da Igreja. As novas formas criadas para as edificações e à inserção de materiais e técnicas construtivas se tornaram elementos essenciais para a transmissão simbólica de significados espirituais imensuráveis na terra. A aproximação das pessoas com a igreja em que participam é o grande meio para a permanência e propagação da religião no século XXI (ARRUDA, 2016).

No Brasil, em especial no extremo Oeste Paulista, o município de Presidente Prudente se consolidou como base de grande importância para a propagação da Igreja Católica no interior do estado de São Paulo. A implantação de uma Diocese em 1960 fomentou a necessidade por expansão dos espaços de culto, em especial a Paróquia Santo Antônio de Pádua. O Bispo Dom José Gonçalves da Costa (1972, Apud. CAVALCANTE; SILVA; SOUZA, 2010, p.412), declarou em 1972 que "atendendo ao crescimento da população e principalmente às necessidades espirituais dos fiéis desta cidade de Presidente Prudente, determinamos criar uma nova paróquia, situada no bairro denominado Jardim Paulista".

A nova Paróquia criada em 1972 é uma das representantes do anseio em se edificar espaços onde os fiéis podem vivenciar as práticas pertinentes a religião Cristã. Mas, além disso, trata-se também de uma edificação que está relacionada com o 
desenvolvimento do município e que demarca algumas mudanças ocorridas que caracterizam a atual cidade. O bairro Jardim Paulista, com origens entre as décadas de 1950 e 1960, apresentava inicialmente características de habitações de baixa renda, por ser naquela época considerado distante do centro. Porém, transformações na década de 1970 acabaram influenciando e consolidando a edificação de um importante espaço sagrado (MACEDO, 2013).

Os fatos que proporcionaram essas mudanças estão relacionados com a modificação no uso do solo em especial da Avenida Washington Luiz, que acabou refletindo diretamente na substituição das classes de renda dos bairros adjacentes. Toda a estrutura urbana da cidade está pautada em quatro avenidas, sendo: Av. Brasil, Av. Manoel Goulart, Av. Coronel José Soares Marcondes e Av. Washington Luiz. As duas primeiras já possuíam edifícios comerciais, porém as outras duas, inicialmente constavam apenas habitações residenciais que, posteriormente, na década de 1970, vieram a ser substituídas por clínicas, consultórios e comércios em geral (MACEDO, 2013).

Com esse cenário, o território que até então era designado para a Paróquia Nossa Senhora do Carmo e para a Paróquia da Catedral de São Sebastião, exercerem suas funções comunitárias foi desmembrado na década de 1970 e passou a constituir a instalação da Paróquia Santo Antônio de Pádua. Esse espaço de culto substituiu a pequena Capela de madeira possuidora das características físicas e sociais da época do surgimento do bairro, e passou a acolher os fiéis católicos pertencentes ao bairro reurbanizado (CAVALCANTE; SILVA; SOUZA, 2010).

Figura 01. Antiga capela em 1967 e atual Igreja Matriz

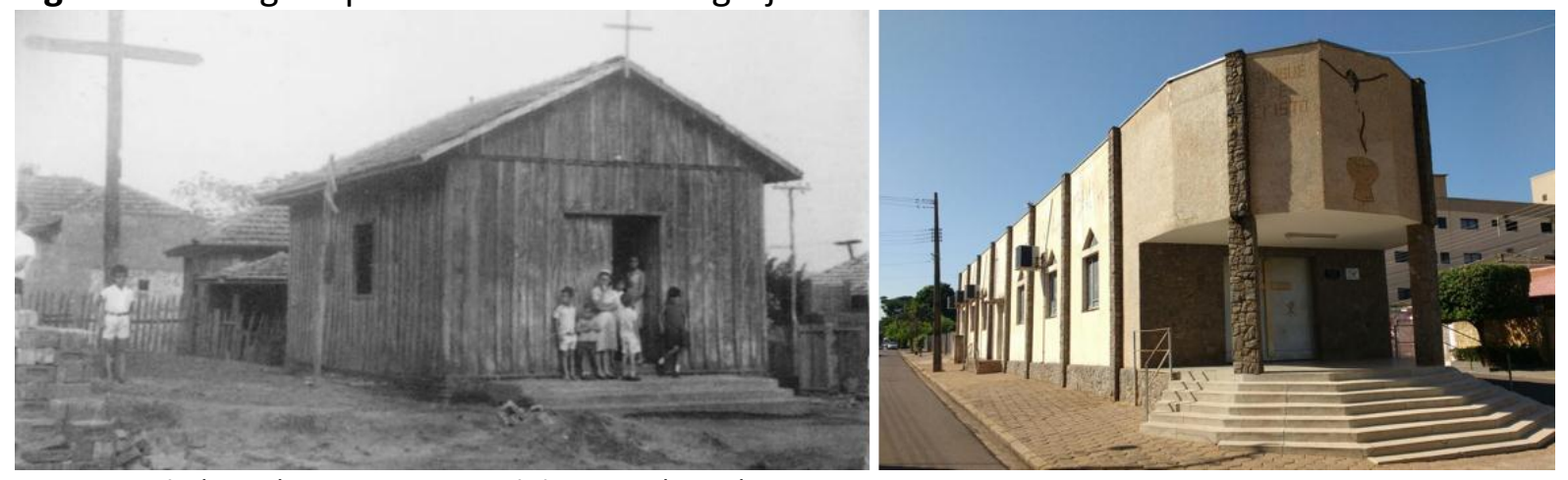

Fonte: Oseki (1967); Arquivo pessoal do autor (2018).

O Bispo Dom José Gonçalves da Costa presidiu no dia 13 de março de 1972 a instauração da Paróquia, sob os cuidados do Padre João Bosco, mas só em dezembro de 1975 que a obra foi concluída, constando o edifício da Igreja Matriz e uma casa paroquial onde funcionou durante anos a secretaria, a residência do sacerdote e algumas salas de reuniões. No ano de 1979, a pedido de Dom Agostinho, um Centro Catequético foi construído nos terrenos da rua ao lado para auxiliar nas atividades e, posteriormente, um lote ao lado foi adquirido para se edificar mais salas para a catequese e demais serviços (CAVALCANTE; SILVA; SOUZA, 2010).

O desenvolvimento da Paróquia Santo Antônio de Pádua foi iminente, tendo, o alcance de inúmeros fiéis dos diferentes bairros que faziam parte do território. Para conseguir atender toda a demanda, foi preciso que novos terrenos fossem adquiridos pela diocese, afim de se construir novas capelas, onde por muito tempo permaneceu associada a Igreja do Jardim Paulista e que depois formou duas novas paróquias de grande expressão na 
cidade, a Santa Luzia e a Santa Teresinha do Menino Jesus (CAVALCANTE; SILVA; SOUZA, 2010).

Pelo reconhecimento ao Padre que iniciou os trabalhos da Paróquia Santo Antônio de Pádua e que permaneceu por quase 32 anos, os paroquianos dedicaram em 1995 como forma de homenagem, uma praça que está inserida em frente à entrada da Igreja Matriz e possui grande valor afetivo no local. Após a sua saída outros sacerdotes assumiram a Paróquia ajudando para o desenvolvimento e a propagação do Catolicismo na cidade de Presidente Prudente.

Figura 02. Igreja Matriz da Paróquia Santo Antônio de Pádua após mudanças.

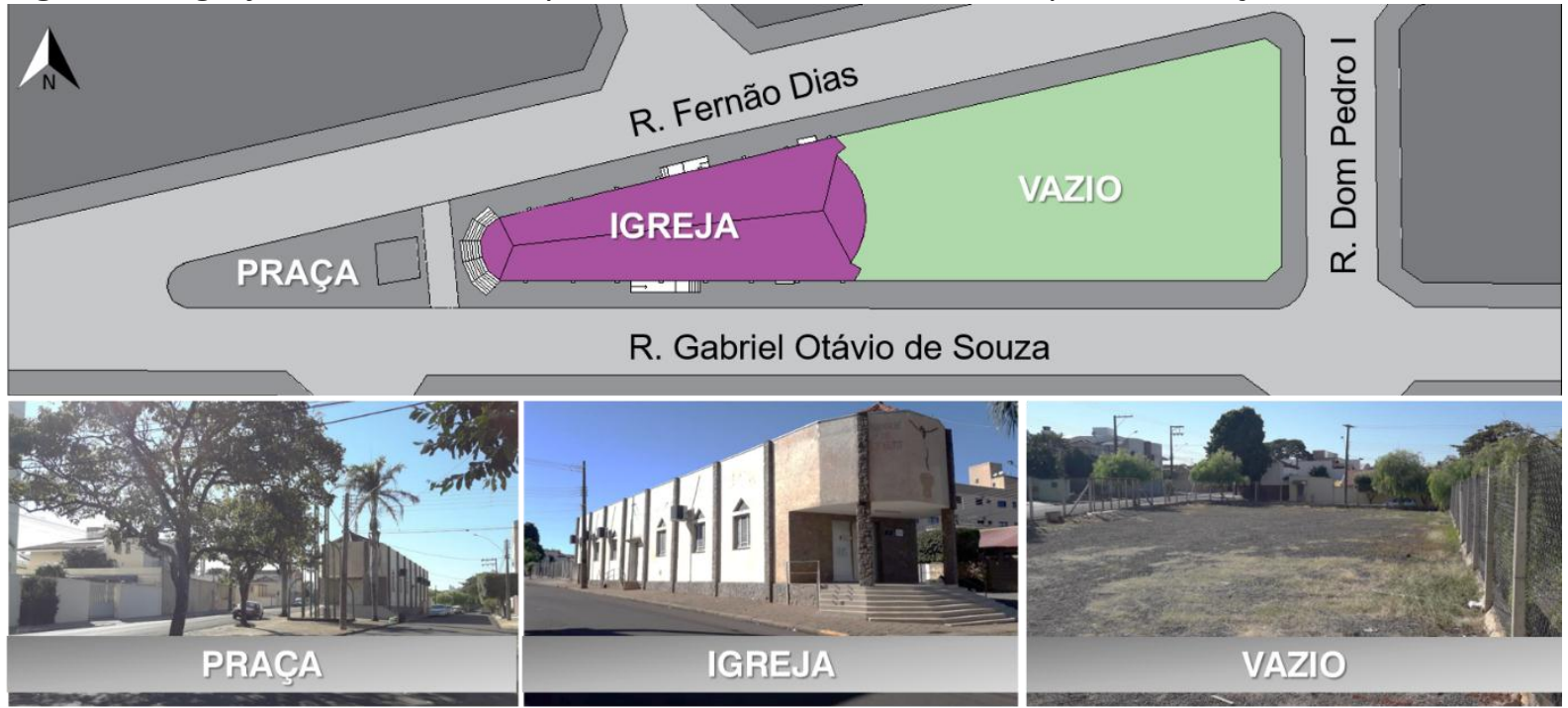

Fonte: Oseki (1967); Arquivo pessoal do autor (2018).

Arquitetonicamente a Igreja Matriz sofreu intervenções que acabaram a descaracterizando tanto na parte externa como na interna, fato que atualmente funciona como barreira para que as propostas do Concílio Vaticano II não sejam totalmente vivenciadas na prática. Para abrigar um projeto de ampliação da Igreja em 2013, que acabou não obtendo êxito, a Casa Paroquial e outras edificações residenciais que existiam ao lado foram demolidas, assim como a sacristia que estava contida no próprio edifício da Igreja.

Figura 03. Rupturas na Igreja Matriz da Paróquia Santo Antônio de Pádua
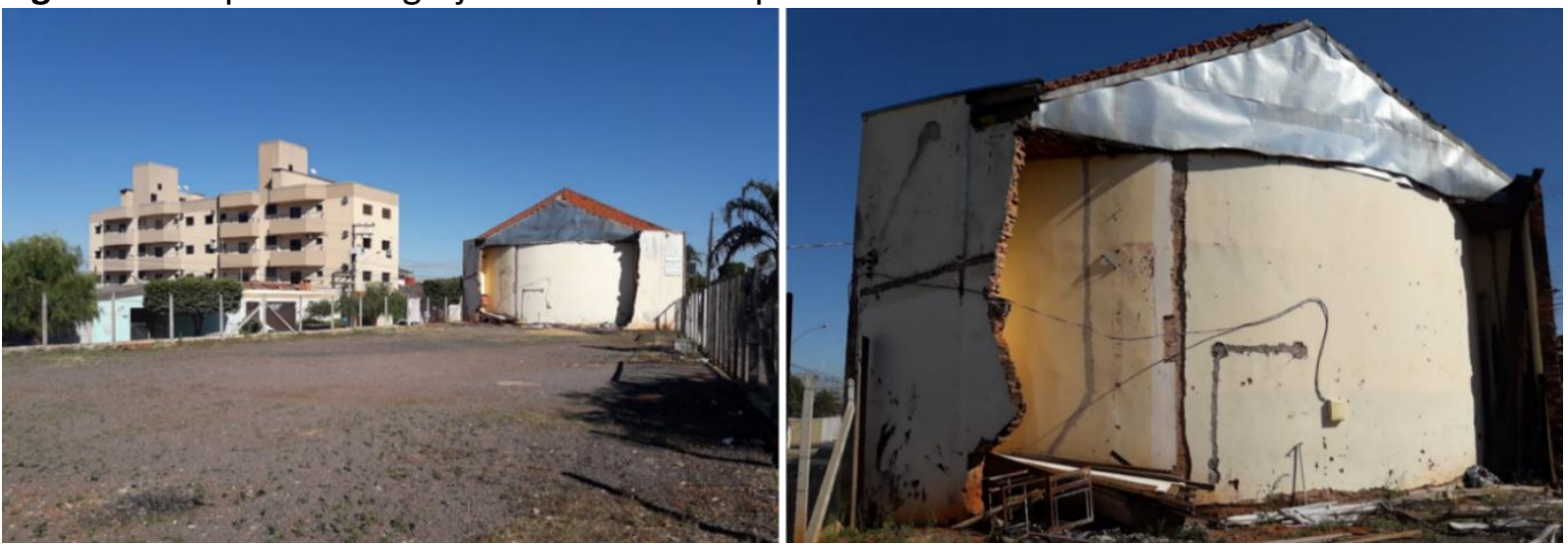

Fonte: Arquivo pessoal do autor (2018). 


\section{CONCLUSÃO}

De um modo geral, o espaço sagrado pertencente ao Jardim Paulista, representa, historicamente, um marco da reurbanização que ocorreu no bairro, pois no mesmo momento em que a prefeitura começou a investir em infraestrutura a diocese substituiu a pequena capela que existia, consagrando assim um edifício que conseguiu durante décadas evangelizar os bairros ao redor. Trata-se de um edificação construída pós Concílio Vaticano II, que foi pensada para o acolhimento e vida em comunidade, mas que por todas as mudanças realizadas fica evidente o anseio por uma requalificação da Paróquia, para que esse dinamismo e relacionamento com a comunidade possa ser cada vez mais potencializado, condicionando um digno local de oração.

\section{REFERÊNCIAS}

ARRUDA, Valdir. Tradição e contradições na arquitetura religiosa brasileira dos anos 1950 . 2016. Disponível em: <http://docomomo.org.br/wp-content/uploads/2016/01/ValdirArruda.pdf $>$. Acesso em 10 fev. 2018.

BRANDÃO, A. A. Espaço Sagrado após Concílio Vaticano II. 1. ed. Minas Gerais: A partilha, 2011.

CAPTIVO, M. T. M. Arquitetura de Espaços Religiosos Contemporâneos. 2016. 119 f. Dissertação (Mestrado em Arquitetura) - Universidade de Lisboa, Lisboa - Portugal.

CAVALCANTE, E. M.; SILVA, C. A. D.; SOUZA, V. A. D. Polianteia Diocesana: Jubileu de Ouro da Diocese de Presidente Prudente. Presidente Prudente: [s.n.], 2010.

FRADE, G. D. S. Arquitetura e liturgia: as contribuições do movimento litúrgico à arquitetura católica paulistana (1933-1962). 2012. 212 f. Dissertação (Mestrado em Teologia) - Pontifícia Universidade Católica, São Paulo - SP.

GYMPEL, J. História da Arquitectura: da antiguidade aos nossos dias. Trad. Virgínia Blanc de Souza. [S.L.]: Konemann, 2001.

MACEDO, R. História de Presidente Prudente. 2013.

OLIVEIRA, H. C. M. D. Espaço e religião, sagrado e profano: uma contribuição para a geografia da religião do movimento pentecostal. Caderno Prudentino de Geografia, Presidente Prudente, n.34, v.2, p.135-161, ago./dez.2012.

RESENDE, L. L. A relação entre o sagrado e o profano na paisagem urbana: A igreja Católica e a Umbanda como agentes atuantes na paisagem de Belo Horizonte. 2015. $141 \mathrm{f}$. Dissertação (Mestrado em Ambiente Construído e Patrimônio Sustentável) - Universidade Federal de Minas Gerais, Belo Horizonte - MG. 